\title{
Digital Media Impact on SMEs Performance in Kingdom of Saudi Arabia
}

\author{
Taha El Haddad* \\ Master Student, University of Business and Technology, Jeddah, Saudi Arabia \\ Sayeeduzzafar Qazi \\ Department of HRM, UNIVERSITY OF BUSINESS AND TECHNOLOGY, SAUDI ARABIA, \\ ORCID: http://orcid.org/0000-0003-1458-3166
}

\begin{abstract}
As well as examine the consequences of the kingdom of Saudi Arabia faces a drop in income, especially with the SMEs due to the Covid-19 and their effect on them. Digital media play an essential role in the impact on SMEs performance in the kingdom of Saudi Arabia. This study aims to identify how different small and medium companies utilize digital marketing; digital networks should be investigated for their impact on firm profitability and examine the consequences of various internet marketing actions on brand exposure. To assess the impact of digital marketing on the efficiency of small and medium enterprises. To test a hypothesis that smaller business uses fewer digital media than the more significant business, an online survey was sent to potential contributors from all around the world. Saudi Arabia is a city called Jeddah. Respondents were randomly divided into two conditions (small and more significant businesses) and asked to respond to the 20 questions. Responses were analyzed using a multiple-choice question. The findings revealed a modest influence in the opposite direction of what had been predicted: big and small businesses use digital media because they think it is the highest score for the people who know them faster. These results suggest that all SMEs must use digital media because it is essential in many ways for the business. On this basis, the digital press must all SMEs know how to use it and treat customers. SMEs must put a budget for marketing because it will be worth it and faster income return to them and save money. Various internet marketing actions on brand exposure.
\end{abstract}

Keywords: Digital Media, SMEs Performance, Social Media Impact, Online Purchase, SMEs Policies.

DOI: $10.7176 / \mathrm{EJBM} / 13-24-05$

Publication date: December $31^{\text {st }} 2021$

\section{Introduction}

Small and mid-size companies (SMEs) with less than a specific revenue, capital, or employees. In the United States, a small \& mid-enterprise (SME) is defined differently than in other countries. Specific size criteria must be satisfied, and the business's sector may also be considered. Modest and mid-size enterprises (SMEs) perform an essential role, given their small capacity. They exceed big companies by such a large percentage, employ a significant proportion of individuals, and are usually entrepreneurial, influencing development. Politicians often offer incentives to help companies remain viable, such as profitable firms and more direct investments. There is no defined technique for classifying small \& mid companies (SMEs). The Eurozone has a lot to offer. According to the criteria, a small company has less than fifty employees, while a mild business has fewer than two hundred fifty employees. However, smaller companies are more often used in the U.S., the U.N., and the Trade Organization all use the term SME. Regardless of language, governments categorize businesses depending on their growth or form. In the industrial sector, an SME is defined as a business with five hundred or fewer workers. On the other hand, metals mining companies may hire up to one thousand five hundred people while still being classed as SMEs. The Internal Revenue Service does not classify businesses as SMEs for tax purposes. Small businesses and individuals are grouped, whereas small and big businesses are divided into two groups. Are inserted into another according to the Internal Revenue Service, small businesses with resources of less than $\$ 10 \mathrm{M}$, while big businesses have resources of much more than $\$ 10 \mathrm{M}$. As a significant corrective effort, all GCC countries agree on the necessity of stimulating the private sector to have a more substantial role in the economy. As a result, supporting SMEs and the private sector as a whole necessitates strengthening the business climate. Saudi Arabia came in fifth place among the GCC countries, with four strong and three weak categories. It has won first place in two categories (Getting Credit and Protecting Minority Investors). Suppose the GCC countries are based on the D.B. category ranking system for 2020. The rating technique distinguishes between the GCC's best and worst D.B. categories, the greatest and six worst. ACCORDING TO THE RANKING STUDY, the UAE is rated top, followed by Bahrain, Oman, Qatar, Saudi Arabia, and Kuwait in the lowest place. Even though UAE won, although it is the highest-ranking GCC member, it does not rank highly in all of its categories. Specifically, UAE is ranked fourth in the Trading across Borders category and ranked first in Starting a business category. Bahrain is the second-most populous country in the Gulf Cooperation Council (GCC). It, like the UAE, does not, however, have a superior rating in all of its categories. The best classes for Bahrain are paying tax and resolving insolvency, where it ranked 
first at both. The worst type for Bahrain is Getting Electricity, where it ranked at sixth position. Saudi Arabia has the third overall ranking position, two categories ranked at sixth (Paying Taxes and Resolving Insolvency) and three categories at second, which are (getting Electricity, getting credit, and enforcing contracts). Oman has four low categories ranked all at fifth position among the GCC countries with only one category is first in GCC, trading across borders. Qatar has the fifth overall ranking position among the GCC countries. Its strongest performances are registering property (ranked first) and Dealing with Construction Permits (ranked second).

On the other hand, Qatar has two weak areas and is rated sixth in the GCC (Protecting Minority Investors and Enforcing Contracts). Finally, Kuwait was the worst performer among the GCC members regarding D.B. as it was ranked dead last at number six. Kuwait has two categories ranked at sixth and five at fifth in Oman's case (W.B., 2020).SMEs in KSA The recently created Small and Medium-Sized Enterprises Administration (www.smea.gov.sa) defines a small and medium enterprise as one having an independent commercial registration and turnover of less than SAR 200 million. The Best SME Development Award is given to the firm that exhibits the most significant and long-term growth.

Saudi Arabia's high-impact dedication, investment, and development in growing its SMEs. SMEs in Saudi Arabia generate about $33 \%$ of GDP and employ nearly $25 \%$ of the workforce, according to (Saudi-US trade organization). Migrant workers make up the majority of Saudi Arabia's SME workforce. Support for SMEs will aid large-scale restructuring by simplifying manufacturing complexes. SMEs break up major corporations' monopolies by providing complementary services and absorbing the ups and downs of the contemporary economy. Small businesses may play a critical role in building a qualified industrial economy and sectors and an excellent service industry that can contribute to GDP growth by providing essential senses. According to the General Statistics Office (GaStat), over 950 thousand (SMEs) existed in Saudi Arabia $88 \%$ of these companies were classified as "mini" at the end of 2017, indicating they employed one to five employees. SMEs used approximately $1 \mathrm{M}$ Saudis and $3.7 \mathrm{M}$ foreigners as of the ending of 2017, accounting for $32 \%$ of all Saudi and $46 \%$ of all expatriates in the labor market, respectively. Small and medium-sized enterprises (SMEs) employ about one million Saudis. Small and medium-sized enterprises (SMEs) accounted for $10 \%$ of the workforce in the manufacturing sector. Finally, it is said that about $41 \%$ of all Saudi small- and medium-sized businesses employ people who are between the ages of 26 and 35, accounting for the most significant proportion of all age groups with 411 thousand workers. The balance of people aged 26 to 35 who work in SMEs is more important.

This suggests that SMEs can Increase the number of employment possibilities available to Saudi youth compared to other businesses. I Digital media may be found in various sectors, including entertainment, technology, eCommerce, non-profit, health, education, and others. As previously said, the main advantage of digital marketing is the ability to reach out to and measure results with a very targeted audience. Another benefit of digital marketing is the rise in brand loyalty, which increases online sales. The following are some of the benefits of digital media for small and medium-sized enterprises (SMEs): Global reach - for a minimal investment, a website may help you find new markets and do worldwide business. Digital marketing campaigns may reach the right consumers at a cheaper cost than conventional marketing methods when they are well-planned and well-targeted, unlike traditional marketing tactics. It is quantifiable and traceable. As a result of using web analytics and other online measurement tools to promote your campaign, it is simple to evaluate its efficacy and efficiency. People's interactions with your website and responses to your advertising may be tracked using Google Analytics, which can provide you with a lot of information. Personalization - If your website is connected to your customer database, you may be able to welcome visitors with customized offers every time they come to your site. The more they purchase from you, the better your customer profile will become, and the more successful you will advertise to them in the future. Communication - By using social media and exercising appropriate control over it, you may build customer loyalty while also establishing yourself as someone easy to interact with. a kind of social money of a specific category. These pieces of material (pictures, movies, and articles) may acquire social value if shared and become viral. The number of people who buy anything has increased. If you have a website, your consumers are just a few clicks away from completing a purchase.

Traditional forms of media, which require customers to get up and make a phone call or visit a shop, maybe smooth and quick compared to digital marketing, which may be soft and fast in contrast to traditional forms of media. When all of these elements of digital marketing are integrated, they have the potential to boost income. The following are some of the drawbacks and issues associated with digital marketing that you should be aware of before you begin: Buying on Social Media Platforms: What You Should Know Purchasing goods and services via In Saudi Arabia, social media networks are prevalent. According to the study, the most popular social media sites for online retail transactions are Snapchat, Instagram, and Twitter.42 percent of individuals who made an online purchase in the previous year did it via social networking websites and apps. Women are more likely than males to make purchases via social media. When compared by nationality, the purchasing behavior of Saudi citizens and non-Saudi ex-pats on social media is quite similar. When consumers use social media for online buying, before purchasing a product or service, it is more convenient to check recommendations and views from other consumers. When a seller participates in social media, consumers get a fantastic sense of transparency from the vendor. Using 
a Smartphone and a Mobile Application Because of Saudi Arabia's high rates of mobile and Internet penetration, 46 technical awareness is rapidly increasing; consequently, sales done through desktop and conventional websites are gradually declining. Shoppers on the internet use smartphones to make purchases 93 percent of the time, compared to just 7 percent who use desktops and laptops for shopping. Those who make purchases using their smartphones are more inclined to make use of mobile applications. Patterns of Online Purchasing by Small and Medium-Sized Enterprises The vast majority of small and medium-sized enterprises (SMEs) surveyed (94 percent) make purchases via internet channels. In contrast, just a tiny proportion ( 5 percent) of the population is involved in ecommerce (i.e., SMEs that use e-commerce in addition to their traditional sales channels). The goods that small and medium-sized enterprises (SMEs) most often buy online include airline tickets, travel insurance, and hotel reservations, as well as I.T. supplies and services, pantry and office supplies are the following most popular choices (which are bought at least once every one to three months). Small and medium-sized enterprises (SMEs) spend an average of SAR 22,450.47 each month on online purchases. When it comes to payment options, The most often used kind is credit cards. This is because they make keeping track of expenditures much simpler.

\section{Review of Literature}

GHANEM, R and HAMID, A (2020) conduct a study on "The Effect of Facebook, WhatsApp, Twitter and Email on S.M.E.s Performance: Empirical Evidence from the United Arab Emirates," according to the studies, they found S.M.E.s' performance in Abu Dhabi, U.A.E. is influenced by equipment for digital marketing (Instagram, WhatsApp, Facebook, and Gmail) indicating that business culture has a mediating effect on social media marketing tools and S.M.E.s' performance. The researchers use a questionnaire to gather extensive information from respondents from S.M.E.s in the United Arab Emirates to obtain a comprehensive picture of the situation.

Al Turais, M (2020) conduct a study on "Enhancing The Performance Of S.M.E.s In Saudi Arabia Through Human capital And Social-Media Technology: A Conceptual Model," They found the contributes to the body of knowledge by offering a complete model that explains the influence of two primary resources in an organization (social media technology use and human capital) on S.M.E.s' organizational performance in Saudi Arabia

Ahmad, S, and Bakar, A and Ahmed, N (2019) conduct a study on "Social media adoption and its impact on firm performance: the case of the U.A.E.," they found The influence of S.M.E.s' use of social media technologies on market success in the United Arab Emirates has been identified, indicating that social media use has minimal impact on the market performance of the study firms. They researched the company's embrace of social media, using its market performance as an endogenous indicator. They conduct an online poll of over 1,000 prospective respondents about the company's financial performance.

Basri, M, and Sha, W (2019) conduct a study on "Social media and corporate communication antecedents of S.M.E. sustainability performance A conceptual framework for S.M.E.s of the Arab world" found that For S.M.E.s operating in the Arab world, social media and corporate communication are critical success factors. The link between digital networking and negotiation skills and the long-term results of the S.M.E. industry is explored in this paper. According to the results of the study, 73 percent of small businesses use social media. In addition, Fourfifths of S.M.E.s $(81 \%)$ wish to expand their digital advertisements, compared to $62 \%$ who don't even - already using social media platforms stating that they would do so in the next calendar year.

Nuseir, M (2018) conducted a study on "digital media impact on S.M.E.s performance in the U.A.E." and found that the use of digital platforms innovative features for S.M.E.s have a good link with company success, particularly in the U.A.E. and the Middle East. They also discovered a loss of skills and a reduced preparedness of S.M.E.s to adopt this fast-developing innovation because they lack a professional staff and talents and a lack of interest in this edition, even though many S.M.E.s are still satisfied driven.

Nuseir, T (2018) conduct a study on "Digital Media Impact On Smes Performance In The U.A.E." According to the studies, They found that Digital media has been hailed as having revolutionary qualities for S.M.E.s, with a positive relationship between D.M. and corporate success, particularly in the Middle East and the U.A.E. According to 83 percent of marketers, the social media ecosystem is critical to their industry. They also uncovered meaningful experiences that might help S.M.E.s in the United Arab Emirates better understand digital In developing nations, innovation and its advantages impact their ability to compete and succeed in business.

Zaidan, E (2017) conduct a study on "Analysis of I.C.T. usage patterns, benefits and barriers in tourism S.M.E.s in the Middle Eastern countries: The case of Dubai in U.A.E." According to the studies, they found With a high amount of smartphone penetration (78 percent), the United Arab Emirates (U.A.E.) provides insight into the application of Information and communication technologies (I.C.T.) that are used by small and medium-sized travel companies in Dubai to communicate with customers. Also identified as a need were More training facilities for travel companies embracing e-commerce and an incentive from the government technical assistance and direction to travel companies operating in the emirate on suitable e-commerce products and services at a reasonable price.

Assimakopoulos, Antoniadis, Kayas, \& Dvizac (2017) conduct a study on "Effective social media marketing strategy: Facebook as an opportunity for universities" They found investigating how undergraduates utilize 
university Facebook (F.B.) groups and forums to learn about their departments and attract students. Furthermore, the factors that can aid the development of a university's Facebook community activities and how Facebook can be utilized as a marketing medium to enhance marketing strategies are explored.

Khatun, A., \& Al-Dhlan, K. A. (2017) Conduct a study on "Effectiveness of WhatsApp: A Social Media Tool for Student's Activities in Saudi Arabia" they found Businesses WhatsApp Marketing Tool is a tool that businesses may use to promote their goods, connect with consumers, and more. Offer their services by sending and receiving textual and multimedia material and seeking early access to the platform. The research Survey 75 Computer Science and Engineering students to determine their thoughts on social media usage and accessibility. They discovered that WhatsApp is one of the most successful methods for enhancing communication between students and instructors and one of the most effective ways to determine the suggested theory's effectiveness.

Dar, A et al., (2017) conduct a study on "Use of Social Media Tool "Whatsapp" in Medical Education" The study looked at a Whatsapp group of students, one for men and one for females, one group of students utilizing Whatsapp In both courses, the lecture subject, related visuals of the taught information, MCQs, and S.E.Q.s were all addressed. Students were invited to raise any concerns they had about the course material or lectures. Additionally, they found that WhatsApp is an essential social networking tool for encouraging, complementing, and perhaps improving undergraduate learning, in addition to conventional classroom teaching.

Swarna (2017) conduct a study on "Impact of Digital Media on Globalization" And found that Personal communication has become more international because of open communication platforms like LinkedIn, Twitter, Skype, Facebook, WhatsApp, and Messenger. They also discovered that the whole globe had been integrated into one society; formerly, only significant corporations were globalized. Thanks to the internet and online trading, even the tiniest micro-enterprise may now be an international employer.

\section{Purpose of the study}

Four years ago, social media was a completely new notion, and many people were completely unaware of it. We didn't know what it was or how it would affect our lives until we encountered it. It was an exhilarating interactive media that rapidly took the world by storm, to the point that no company, big or small, local or global, could afford to ignore it anymore. As a small business owner, you may find online marketing daunting at first since it can be tough to decide where to concentrate your efforts. Therefore, since social media marketing is a vast subject with a complex hierarchy, there is an interest in becoming familiar with it and learning about the plan or strategy employed by small and micro-businesses. One of the study's goals is to investigate how Micro and Small Businesses may use social media to penetrate their markets, reach out to customers, and build connections in a personal and direct manner that can rocket their brand and raise their recognition much like a big corporation. This investigation provides information on the influence of social media on online buying choices and behavior.

\section{Research Objectives}

To identify the many micros and small businesses that use social media for advertising their products or services.

To investigate the influence of social media on business results.

To investigate the effects of various internet promotional efforts on brand awareness.

This study aims to examine how micro and small businesses perform after using social media marketing strategies.

\section{Research Methodology \\ Sample size and Techniques:}

The research examines 50 S.M.E.s in the food and health industries. 25 When it comes to gathering statistics on the usage of social media for business and the impact on small and medium-sized enterprises (S.M.E.s) in the food and health sectors, participation of micro and small businesses in social media for a company, which covered a large population and made it impossible to collect data using a census methodology, a sampling method was used. As a consequence, a justifiable sampling procedure is followed. Because of time and financial limitations, data gathering from a large sample was a significant step backward. As a result, a convenience sampling method with a low chance of success was used. Snowball sampling was also used on purpose in this study. One person who qualified to participate was asked to recommend many other individuals familiar with social media, and the list of participants expanded as a result.

Methods of data gathering include the following:

The quantitative data collecting technique is being used to make it easy to summarize, compare, and generalize the findings obtained from the study. Techniques for primary data collection were used.

The following is the primary data collecting method:

For the survey, online research questionnaires were created for the S.M.E.s in K.S.A. Jeddah in the food and health care sectors, housed in the exact location. in the links https://forms.gle/MDmVMtbc4KXbR8fc6

Data Collection procedure: 
The data from the chosen sample was collected using online instruments explicitly created for this study. The Google form service was used to develop the tool. This project required the creation of a new Google account. For each case, the forms were employed, and the information gathered was analyzed. The responders' data was kept private. The generated URLs were shared on social media sites and also delivered over WhatsApp to accessible friends.

Types of inquiries:

Multiple Choice closed-ended questions were used to classify the questionnaire since This makes them ideal for gathering statistical information and percentages. Closed-Ended Importance Questions are a kind of closed-ended importance question that may be answered in any way.

\section{Tools used and questionnaire}

Everyone who may be interested in participating got an email invitation that included a thorough description of the research as well as a link to the survey website. Online surveys provide a one-of-a-kind method of gathering information from a large number of individuals. There are many advantages to doing an online survey, including a large sample size and therefore greater statistical power, the ability to gather large amounts of data, and the availability of validated models. A total of 20 questionnaires were distributed, with 50 valid responses coming from individuals who work in a variety of SMEs in the food and health sectors. The second-order constructs were evaluated using a two-step approach, which allowed for the prediction of a more parsimonious model to be predicted. To keep track of responses, a The researchers employed a five-point Likert scale ( 1 = "strongly disagree"; 5 = "strongly agree"). with a $1=$ "strongly disagree" response option. They will conduct a survey that will take about ten minutes to complete. Included in the research are questions on communication and its impact on food and beverage SMEs health industries. In order to accurately reflect the general characteristics of the study's participants, we will also ask for certain demographic information (such as age, marital status, number of workers, and educational level) from the participants.

\section{Result and Discussion}

the above pie graph tells us that $90 \%$ from the responses are using digital media and only $10 \%$ stop filling out this form.

\section{Do you use digital media?}

39 responses

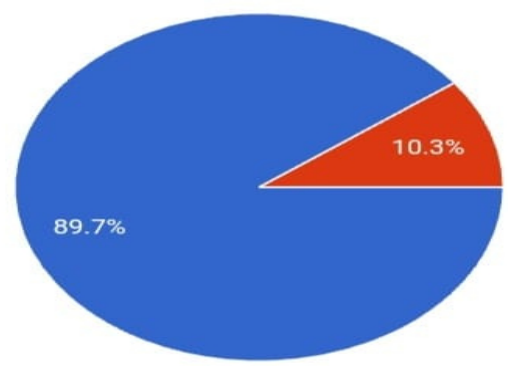

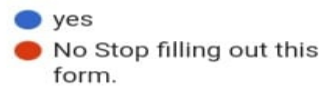

form.

The above pie graph tells us that most responses preform Instagram by $67.5 \%$ then other application like WhatsApp $12.5 \%$ and Facebook $7.5 \%$.
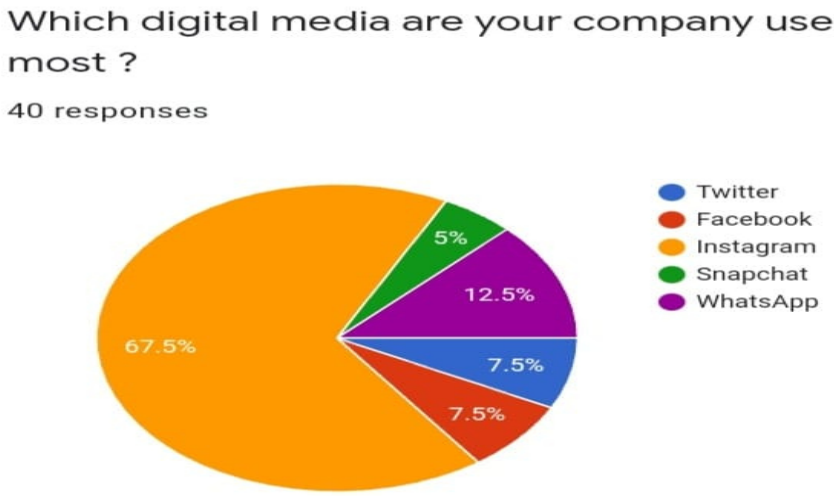

The above pie graph tells us that most of the responses are telling that digital media is very important to the 
Do you think related to your numbers advertisements appearing on your social media profile are relevant for your company?

40 responses

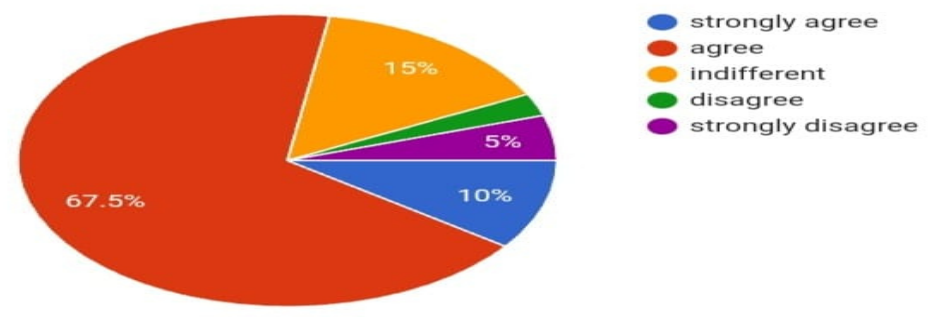

The above pie graph indicates that out of 40 respondents $85 \%$ agrees on The utility of social media to enhance the frequency of selling items online or using online services is disputed and only indifferent and disagree both with only $7.5 \%$
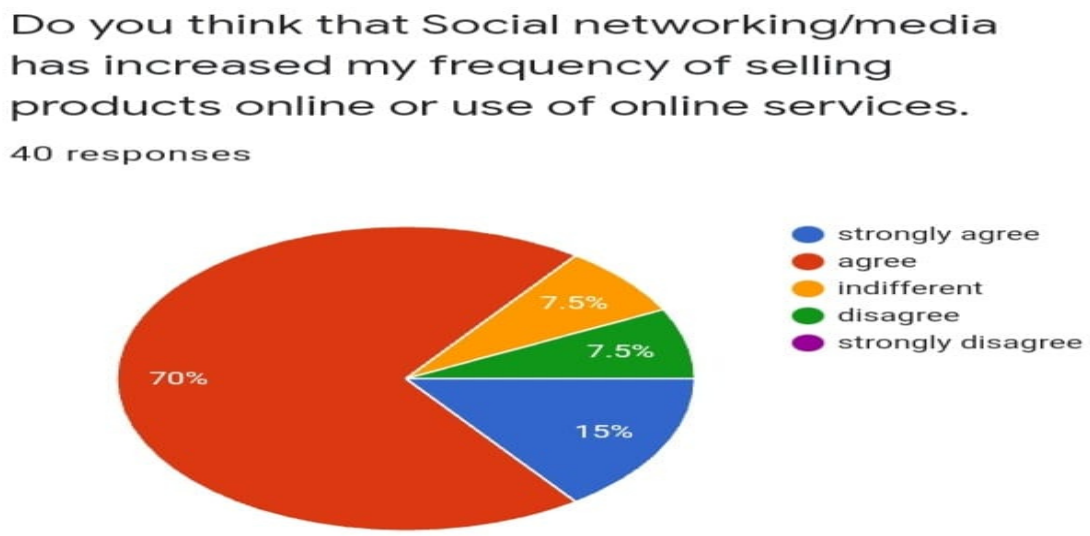

The above pie graph indicates that out of 40 respondents 77.5 agrees that due to social media people effects the buying decisions by making their own review and the rest are disagreed with $2.5 \%$ and $5 \%$ strongly disagree.
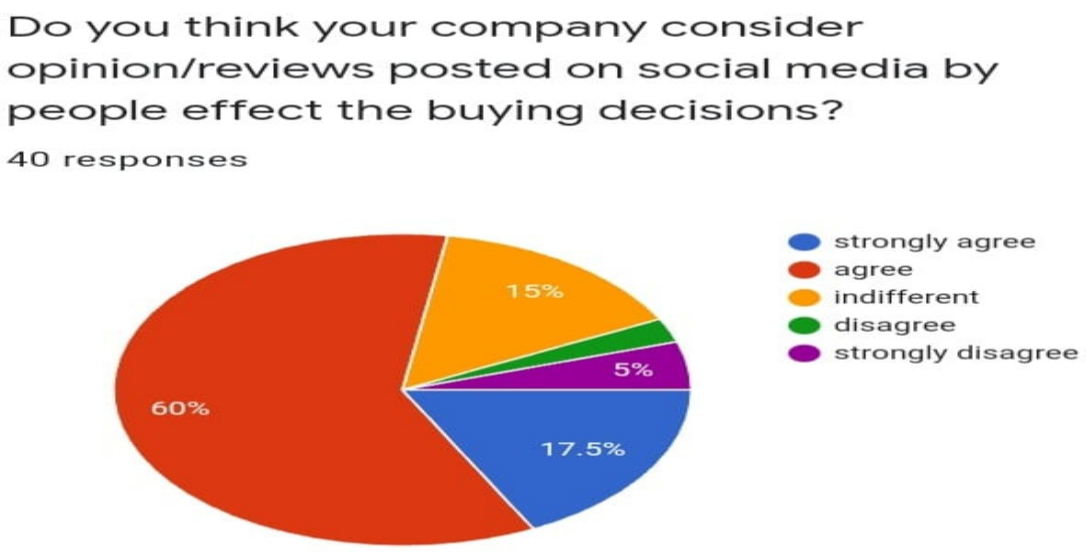

The above pie graph indicates that out of 40 respondents $80 \%$ agrees that social media save money and time in food and health sectors and the rest are not disagree with $2.5 \%$ and $7.5 \%$ strongly 

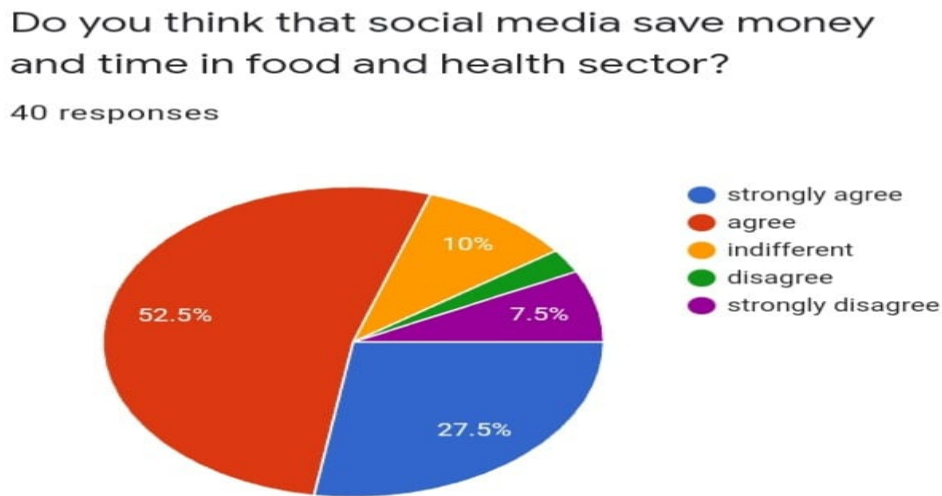

The above pie graph indicates that out of 40 respondents mostly $90 \%$ think that social media spread your advertising to your product faster than the traditional way and only $10 \%$ are indifferent and no one have been disagree.
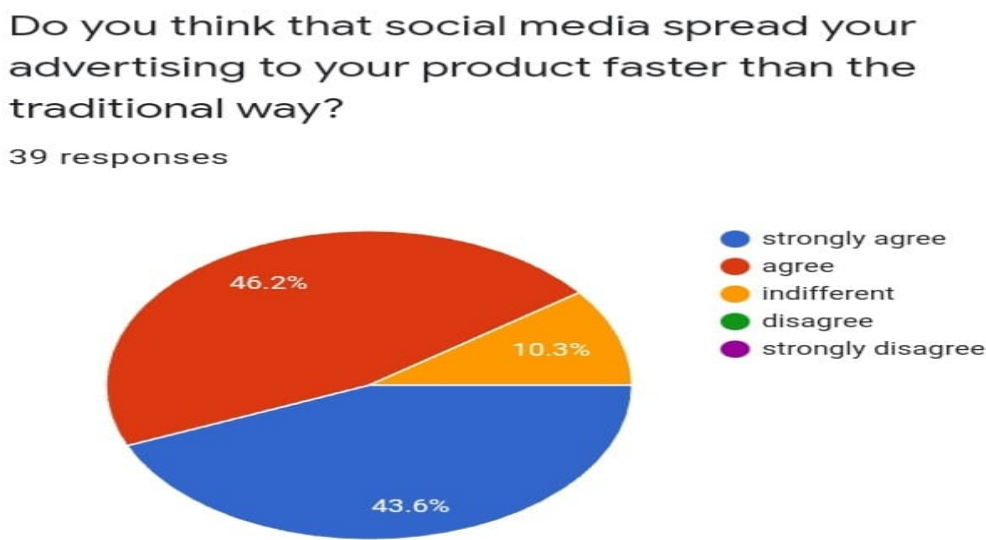

The above pie graph indicates that out of 40 respondents $85 \%$ agree that social media make life immune from pandemics like Covid-19 and only 10\% indifferent and 5\% disagree.

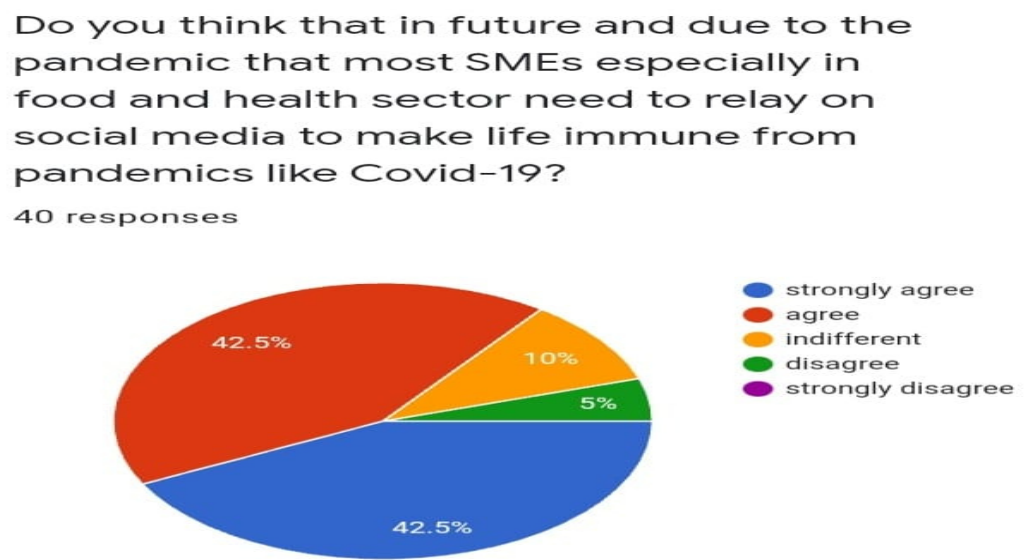

Based on the 20 questions, I conclude that most responses think that social media is essential in spreading their ideas, work, and advertising. Social media make life easier and make jobs done faster. Some of the responses think that they can't get social media and don't like it because it spread your success. Still, also it makes you drop down because of the large number of completion and the review of people it spread faster if the product or service, and this will also affect the income of them if it is a negative review. All the responses agree that social media play an essential role in economic and advertising and saving money. Still, some are afraid to enter it, or he doesn't know how to use it, and some are using the social media well and get the advantage in using it. Some of the responses working in a big firm are using social media, and they put a yearly budget for it, and all agree that social media is the present and the future of the financial world. 


\section{Conclusion and Suggestions: Conclusions}

Business entities classified as small and mid-size (SMEs) have revenues, assets, or employees that fall below a certain threshold in terms of size. The term "small \& mid business" (SME) is defined differently in each nation (SME). Specific size requirements must be fulfilled, and the business's industry may also be considered. Despite their modest size, Small and mid-businesses (SMEs) are vital to the economy and society. They outnumber big companies by a vast proportion, employ many people, and are often entrepreneurial, contributing to the advancement of technology. Governments often offer incentives to companies to keep them afloat, such as favorable tax treatment and easier access to funding. Many individuals had no clue what social media was or how it would impact their lives four years ago when the notion had only emerged from the obscurity of obscurity. It was an exhilarating interactive medium that rapidly swept the world, to the point that no company, huge or tiny, local or global, could afford to ignore it any longer. Small business owners first considered online marketing daunting since it was difficult to track the results of their efforts. Therefore, since social media marketing is a vast subject with a complex hierarchy, there is an interest in becoming familiar with it and learning about the plan or strategy employed by Small and micro-businesses. The study's goal is to determine how Micro and Small Businesses can use social media to infiltrate their markets, reach out to customers, and build connections in a personal and direct way that can rocket their brand and boost their recognition as effectively as or more effectively than any major corporation. This investigation provides information on the influence of social media on online buying choices and behavior.

\section{Suggestions}

I suggest that all SMEs use digital media because it helps them speed their ideas and message faster to the customers and save them money and time. Due to the survey that I have done, I see many SMEs are open to using digital media because all the world is used to technology, and they want a faster way of taking the message from the receiver. No of their size, small and mid-size businesses (SMEs) are critical contributors to the economy's overall health. They outnumber more prominent companies by a significant margin, employ a considerable number of people, and are usually entrepreneurial. They are influencing innovation. Governments regularly give incentives to help firms stay viable, such as favorable tax treatment and easier access to funding. As a result, the government should support SMEs by creating a presence in digital media, which would tremendously benefit them; this would be a win-win scenario for everyone, as SMEs are essential to any country's economic success.

\section{References}

- $\quad$ Ahmad , S and Bakar, A and Ahmed, N (2019) conduct a study on " Social media adoption and its impact on firm performance: the case of the UAE" Vol. 25 No. 1, 2019.

- Al Turais , M (2020) conduct a study on " Enhancing The Performance Of SMEs In Saudi Arabia Through Human capital And Social-Media Technology: A Conceptual Model" Vol. 2, No. 01; 2020

- Aleid, E. (2015). Delivery Issues in E-Commerce: The Case of Saudi Arabia (Master's thesis). University of Waikato.

- Al-Khalidi, F. (2015). Ecommerce in the Arab world - The infographic - The payfort blog. Retrieved from http://www.payfort.com/blog/ecommerce-arab-world-infographic/

- Al-Khalidi, F., Abdalla, N., Soudodi, O., \& Syed, S. (2015). State of payments 2015. Retrieved from http://stateofpayments.com/\#ecommerce

- $\quad$ AlSharji, A., Ahmad, S. Z., \& Bakar, A. R. A. (2018). Understanding social media adoption in SMEs. Journal of Entrepreneurship in Emerging Economies.

- $\quad$ Arnone, L. \& Deprince, E. (2016). Small firms internationalization: Reducing the psychic distance using social networks. Global Journal of Business Research, 10(1), 55-63.

- $\quad$ Assimakopoulos, C., Antoniadis, I., Kayas, O. G., \& Dvizac, D. (2017). Effective social media marketing strategy: Facebook as an opportunity for universities. International Journal of Retail \& Distribution Management.

- $\quad$ Basri, W. (2016). Social media impact on small and medium enterprise: Case review of businesses in the arab world. Arts and Social Science Journal, 7(6), 236.

- $\quad$ Basri, W. S. M., \& Siam, M. R. (2019). Social media and corporate communication antecedents of SME sustainability performance. Journal of Economic and Administrative Sciences.

- Cesaroni, F.M. \& Consoli, D. (2015). Are small businesses really able to take advantage of social media?.Electronic Journal of Knowledge Management, 13, 257-268.

- Cheng, M. (2015). Saudi arabian e-commerce plays key role in widespread use of electronic payments | Payment Week. Retrieved from http://paymentweek.com/2015-3-23-saudi-arabian-e-commerceplays-keyrole-in-widespread-use-of-electronic-payments-6882/ 
- $\quad$ Dar, Q. A., Ahmad, F., Ramzan, M., Khan, S. H., Ramzan, K., Ahmed, W., \& Kamal, Z. (2017). Use of social media tool "Whatsapp" in medical education. Annals of King Edward Medical University, 23(1).

- GHANEM, R and HAMID, A (2020) conduct a study on The Effect of Facebook, WhatsApp, Twitter and Email on SMEs Performance: Empirical Evidence from United Arab Emirates. IBIMA Publishing Journal of Internet Social Networking \& Virtual CommunitiesVol. 2020 (2020), Article ID 618899, 17 pages.

- Khatun, A., \& Al-Dhlan, K. A. (2017). Effectiveness of WhatsApp: A Social Media Tool for Student's Activities in Saudi Arabia. International Journal of Technology and Educational Marketing (IJTEM), 7(2), $17-23$

- Locke, S. (2016). The National: Marketing professor explores strategies for SMEs in the UAE [Online] Available at https://www.thenational.ae/business/marketing-professor-explores-strategies-for-smes-in-theuae-1.203753 [Accessed September 14, 2017].

- $\quad$ Makki, E and Ching Chang, L (2015) conduct a study on Understanding the Effects of Social Media and Mobile Usage on E-Commerce: An Exploratory Study in Saudi Arabia. International Management Review Vol. 11 No. 22015

- $\quad$ Makki, E., \& Chang, L. C. (2015). Understanding the effects of social media and mobile usage on ecommerce: an exploratory study in Saudi Arabia. International management review, 11(2), 98.

- Nelson, C. (2016). The National: UAE's global top spot in smartphone use gives local SMEs huge opportunities. [Online] Available at https://www.thenational.ae/business/technology/uae-s-global-top-spotin-smartphoneuse-gives-local-smes-huge-opportunities-1.175824 [Accessed on September].

- Nuseir, M. T. (2018). Digital media impact on SMEs performance in the UAE. Academy of Entrepreneurship Journal.

- $\quad$ Nuseir,M(2018) Digital media impact on smes performance in the UAE. Academy of Entrepreneurship Journal,Volume 24, Issue 2, 2018

- $\quad$ Odoom, R., \& Mensah, P. (2018). Brand orientation and brand performance in SMEs: The moderating effects of social media and innovation capabilities.

- Olanrewaju, A. S. T., Hossain, M. A., Whiteside, N., \& Mercieca, P. (2020). Social media and entrepreneurship research: A literature review. International Journal of Information Management, 50, 90-110.

- Samuel, B.S. \& Sarprasatha, J. (2016). Entrepreneurship in social-media services in Oman: A socio-economic scanning of the sultanate. Asian Social Science, 12, 138-148.

- Swarna, M. (2017). Impact of new digital media on globalization. [Online] Available at: https://www.scribd.com/doc/178441381/Impact-of-New-Digital-Media-on-Globalization [Accessed 22 August 2017].

- Zaidan, E. (2017). Analysis of ICT usage patterns, benefits and barriers in tourism SMEs in the Middle Eastern countries: The case of Dubai in UAE. Journal of Vacation Marketing, 23(3), 248-263. 